\title{
Malatya yöresinde yetiştirilen mahalli 'Karamehmet' elmasında seleksiyonla verimli ve kaliteli klonların seçimi
}

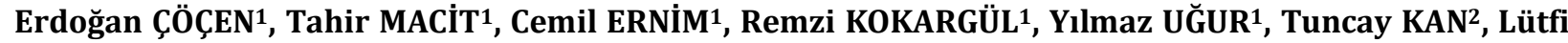 \\ PIRLAK $^{3}$
}

\author{
${ }^{1}$ Kayısı Araștırma Enstitüsü Müdürlüğü, Malatya \\ ${ }^{2}$ Malatya Turgut Özal Üniversitesi Ziraat Fakültesi Bahçe Bitkileri Bölümü, Malatya \\ ${ }^{3}$ Selçuk Üniversitesi Ziraat Fakültesi Bahçe Bitkileri Bölümü, Konya
}

Alınış tarihi: 14 Ocak 2019, Kabul tarihi: 29 Mart 2019

Sorumlu yazar: Erdoğan ÇÖÇEN, e-posta: elmas29@gmail.com

\section{$\ddot{0} \mathbf{z}$}

Elma insan sağlığı ve beslenmesinde önemli olan, her mevsim pazarda bulunabilen, ekonomik, lezzetli ve yaygın şekilde tüketilen bir meyvedir. Ülkemiz elma üretiminde ticari değeri yüksek standart çeşitlerin yanı sıra çok sayıda mahalli çeşitler de yer almaktadır. Bu mahalli çeşitler ıslah çalıșmaları için önemli bir genetik kaynak oluşturmaktadır. Malatya ilinde yetiștirilen mahalli Karamehmet elması; eylül ayı başında olgunlaşır. Yeme kalitesi ve albenisi yüksek, ince kabuklu, hoş kokulu, hafif mayhoştatlımsı, gevrek ve suludur. Malatya ilinde 20132017 yılları arasında yürütülen bu çalışmada, farklı genotiplerinin olduğu gözlenen Karamehmet elmasında kaliteli klonların belirlenerek üretime kazandırılması amaçlanmıştır. Alan taramasında yapılan incelemelerde verimli ve sağlıklı olduğu gözlenen 15 klon arazide işaretlenmiştir. İşaretlenen ağaçlardan alınan meyve örneklerinde pomolojik analizler gerçekleştirilmiş ve elde edilen veriler "Tartılı Derecelendirme Metodu" ile değerlendirilmiștir. Değerlendirme sonunda, "Karamehmet" elma çeşidinde 44.KM.02, 44.KM.08 ve 44.KM.15 no'lu klonlar ümitvar bulunmuştur. Ümitvar klonlarda meyve ağırlı̆̆ı $151.98 \mathrm{~g}$ (44.KM.08) ile $205.30 \mathrm{~g}$ (44.KM.02), meyve eti sertliği $7.90 \mathrm{~kg} / \mathrm{cm}^{2}$ (44.KM.02) ile $8.90 \mathrm{~kg} / \mathrm{cm}^{2}$ (44.KM.15), suda çözünebilir kuru madde (SÇKM) oranı \%13.12 (44.KM.02) ile \%14.10 (44.KM.15), TEA değeri \% 0.70 (44.KM.15) ile \%1.12 (44.KM.08), pH değeri ise 2.20 (44.KM.08) ile 3.65 (44.KM.15) arasında değișmiștir. Çalışma sonunda; periyodisite eğilimi göstermeyen, verimli, yeme kalitesi ve albenisi yüksek olduğu belirlenen bu ümitvar klonlar çoğaltılarak Kayısı Araştırma Enstitüsü Müdürlüğü koleksiyon parseline dikilmiştir.

Anahtar kelimeler: Elma, seleksiyon, yerel çeşit, periyodisite

Selection of fruitful and quality clones in local "Karamehmet" apple variety grown in Malatya province
Abstract
Apple is a delicious and economic fruit that is important in human health and nutrition, which can be found in every season in the market, and consumed widely. In apple production in our country, in addition to standard varieties with high commercial value, there are also many local varieties. These local varieties constitute an important genetic resource for breeding activities. The local "Karamehmet" apple variety grown in the province of Malatya ripens in early September. The eating quality and attractiveness are high, and it is thin-peel, odiferous, crispy and juicy with mild sour to sweetish taste. In this study, which was carried out between 2013-2017 in Malatya province, it was aimed to introduce them into production by determining high quality clones in the "Karamehmet" apple, which has different genotypes. In the field survey, 15 clones observed to be abundant in fruit and healthy were marked in the 
field. Pomological analyzes were performed in the fruit samples taken from the marked trees and the data were evaluated with the "Weighted Ranked Method". At the result of the evaluation, clones of 44.KM.02, 44.KM.08 and 44.KM.15 were determined as hopeful clones in "Karamehmet" apple variety. In the hopeful clones, the average fruit weight was ranged from $151.98 \mathrm{~g}$ (44.KM.08) to $205.30 \mathrm{~g}$ (44.KM.02), fruit flesh firmness $7.90 \mathrm{~kg} / \mathrm{cm}^{2}$ (44.KM.02) to $8.90 \mathrm{~kg} / \mathrm{cm}^{2}$ (44.KM.15), total soluble solids (TSS) $13.12 \% \quad$ (44.KM.02) to $14.10 \%$ (44.KM.15), titratable acidity $0.70 \%$ (44.KM.15) to $1.12 \%$ (44.KM.08) and pH 2.20 (44.KM.08) to 3.65 (44.KM.15). At the result of the study, hopeful clones that showed no tendency to periodicity, which is abundant in fruit, the attractiveness and the high eating quality were planted to the collection parcel of Apricot Research Institute.

Key words: Apple, selection, local variety, periodicity

\section{Giriş}

Yumuşak çekirdekli meyvelerden olan elma; vitamin, mineral madde, antioksidan ve fotokimyasal içeriği bakımından zengin olup, insan sağlığı ve beslenmesinde önemli yeri olan bir meyve türüdür. Tüketicilerin yoğun olarak tercih ettiği elma, pazarda her mevsim bulunabilen lezzetli bir meyvedir (Küçükömürler ve Karakuş, 2009). Elmanın bedeni ve zihni yorgunluklara, büyüme çağındaki çocukların gelişimine, sindirim sisteminin düzenli çalışmasına, cildin güzelliğine, kansızlığa, kan şekerinin düşürülmesine, hafızanın güçlenmesine, öksürüğe, kabızlığa, diș sağlığına, kanın temizlenmesine, solunum rahatsızlıklarına, kan dolaşımının düzelmesine ve kolesterolün düşürülmesine iyi geldiği bildirilmektedir (Anonim, 2009).

Rosales takımı Rosaceae (Gülgiller) familyasında yer alan elmanın anavatanı; Anadolu, Kafkasya ve Türkistan'dır. Elmanın anavatan bölgesi içerisinde yer alan Anadolu'nun hemen her bölgesinde elma yetiştiriciliğine rastlamak mümkündür (Kaşka, 1997).

İstatistiki veriler incelendiğinde 2016 yllında 89.329.182 ton olan dünya toplam elma üretiminin \% 3' lük kısmının ülkemizde gerçekleştiği ve üretim miktarı bakımından dünyada 4. sırada yer aldığımız görülmektedir (FAO, 2018). Ülkemizde 2016 yllında üretilen 2.925.828 tonluk toplam elma üretiminin; \% 39' unu Starking, \%16' sinı Golden, \% 8' ini Amasya,
\% 4' ünü Granny Smith ve \% 23' ünü ise diğer çeşitler oluşturmaktadır (TUİK, 2018).

Ülkemiz elma üretiminde ticari değeri yüksek standart çeşitlerin yanı sıra henüz ticari değere ulaşmamış çok sayıda mahalli çeşitler de yer almaktadır. Bu mahalli çeşitler bir taraftan farklı bir damak tadı sunarken, diğer taraftan yeni çeşitlerin geliștirilmesinde önemli bir genetik kaynak oluşturmaktadır (Çöçen ve ark., 2018). Bugün dünya elma ticaretine konu olmuş çeşitlerin pek çoğu bu ıslah çalışmaları sonucunda ortaya çıkarılmıştır (Kaçal ve ark., 2009). Karlıdağ ve Eşitken (2006), ülkemizdeki mahalli meyve çeşitlerimizin özelliklerinin belirlenerek koruma altına alınmasının yeni çeşitlerin geliştirilmesinde önemli olduğunu belirtmektedir.

Malatya kayısı üretimiyle öne çıkmakla birlikte, ikliminin uygun olmasıyla diğer birçok meyve türünün de başarıyla yetiștirildiği bir ildir (Bayındır ve ark., 2018). Malatya ilinin önemli bir meyve üretim bölgesi olduğunu belirten Ülkümen (1938), ilde yaptığı bir çalışmada mahalli olarak yetiştirilen 26 elma, 12 armut ve 6 kayısı çeşidi tespit etmiştir. İlde elma üretimi kayısıdan sonra ikinci sırada yer almaktadır. İlin elma üretim alanlarında standart çeşitlerin yanı sıra mahalli elma çeşitlerinden 'Karamehmet' elmasının da üretildiği görülmektedir.

Karamehmet elması meyve kalitesi ve albenisiyle tüketiciler için yeni bir çeşit olarak öne çıkmaktadır. Yapılan incelemelerde farklı genotiplerinin olduğu gözlenen bu mahalli çeşitte kaliteli klonların belirlenerek üretime kazandırılması önem arz etmektedir. Tarım ve Orman Bakanlığı'nca desteklenen ve 2013-2017 yılları arasında yürütülen bu çalıșmada Malatya ilinde mahalli olarak yetiştirilen Karamehmet elmasında üstün özellikli klonların seleksiyonu amaçlanmıştır. Çalışma sonunda belirlenen ümitvar klonların tescillenerek üretime kazandırılması hedeflenmektedir.

\section{Materyal ve Yöntem}

\section{Materyal}

Çalışmanın materyalini Malatya ve yöresinde yetiştirilen yöresel Karamehmet elma çeşidine ait klonlar oluşturmuştur. Karamehmet elmasının meyveleri silindirik yapıda, beyaz-krem zemin üzerine parlak kırmızı renkte, çiçek çukuru derince ve geniş yapıdadır. Eylül ayının ilk haftasında olgunlaşan bu çeşit; yeme kalitesi ve albenisi yüksek, ince kabuklu, hoş kokulu, hafif mayhoş-tatlımsı, gevrek ve suludur (Şekil 1). 


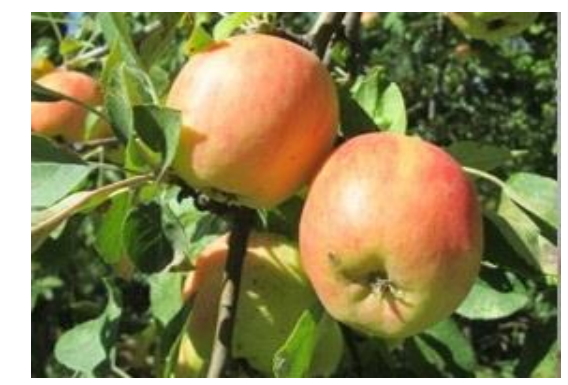

Şekil 1. Karamehmet elması

\section{Yöntem}

Çalışmada ilk olarak arazi tarama programına göre taramalar yapılmıș, kaliteli meyvelere sahip, verimli ve sağlıklı olduğu gözlenen farklı klonlar işaretlenmiştir. Pomolojik analizler için, işaretlenen bu ağaçlardan meyve olum döneminde rastgele 10' ar adet meyve örneği alınmıştır. Pomolojik analizlerde meyve ağırlı̆ $0.01 \mathrm{~g}$ hassasiyetindeki terazi ile tartılarak ortalama değerleri alınmıș, meyve boyu, meyve çapı, meyve sapı uzunluğu, sap çukuru derinliği ve çiçek çukuru derinliği ise 0.01 mm'ye duyarlı kumpas ile ölçülerek ortalama değerlerinin alınmasıyla belirlenmiștir (Burak ve ark., 1997). Meyve eti sertliği ölçümü el penetrometresi ile $11.1 \mathrm{~mm}$ çapındaki penetrometre ucu kullanılarak gerçekleștirilmiş ve belirlenen değerlerin ortalaması meyve eti sertliği olarak kaydedilmiștir (Pearce, 1976). Meyve kabuk rengi, her genotipte hasat döneminde pomolojik analizler için alınan meyvelerde 'Minolta Chromo Meter CR400' cihazı kullanılarak L, a, b cinsinden belirlenmiştir. Suda çözünür kuru madde miktarı (\% SÇKM) el refraktometresiyle, $\mathrm{pH}$ değeri ise elde edilen meyve suyunda $\mathrm{pH}$ metre ile ölçülmüștür. Titre Edilebilir Asitlik (\% TEA) ölçümü, meyve suyunda fenol ftaleyn indikatörü yardımıyla $0.1 \mathrm{~N}$ $\mathrm{NaOH}$ ile titre edilmiş ve sonuçlar malik asit cinsinden titrimetrik yöntem kullanılarak belirlenmiştir (Altan, 1989). Klonların periyodisite eğilimi ve verimlilik durumları arazide gözlenerek belirlenmiştir. Meyvelerin albeni ve yeme kalitesi beş kişiden oluşan jüri tarafından duyusal olarak 1-5 arasında puanlanmıştır.

Verilerin değerlendirilmesinde 'Tartılı Derecelendirme Yöntemi' kullanılmıştır. Tartılı derecelendirmede dikkate alınan özellikler, görece puanlar ve sınıf aralıkları Çizelge 1'de verilmiştir.

\section{Bulgular}

$\mathrm{Bu}$ çalışma, Malatya ilinde yetiştirilen mahalli Karamehmet elma çeşidinde üstün özellikli ümitvar klonların belirlenmesi amacıyla yürütülmüştür. Çalışmada ilk önce kaliteli meyvelere sahip, verimli ve sağlıklı olduğu gözlenen 15 klon arazide işaretlenmiştir. Çögür anacına aşılı, yaklaşık 15-25 yaşlarındaki bu ağaçların konum ve hasat dönemi bilgileri Çizelge 2'de verilmiştir.

Çizelge 1. Tartılı Derecelendirme kriterleri, görece puanlar ve sinıf aralıkları

\begin{tabular}{|c|c|c|c|}
\hline Kriterler & $\begin{array}{l}\text { Görece } \\
\text { puanlar }\end{array}$ & Sınıf Değerleri & Puanları \\
\hline \multirow{3}{*}{$\begin{array}{l}\text { Meyve İriliği } \\
\text { (g) }\end{array}$} & \multirow{3}{*}{20} & $\mathrm{~g}>200$ & 10 \\
\hline & & $100-199$ & 7 \\
\hline & & $\mathrm{g}<99$ & 4 \\
\hline \multirow{3}{*}{ Verimlilik } & \multirow{3}{*}{20} & İyi & 10 \\
\hline & & Orta & 7 \\
\hline & & Kötü & 4 \\
\hline \multirow{3}{*}{ Periyodisite } & \multirow{3}{*}{15} & Yok & 10 \\
\hline & & Kısmi & 5 \\
\hline & & Var & 1 \\
\hline \multirow{3}{*}{ SÇKM (\%) } & \multirow{3}{*}{10} & $\%>13.00$ & 10 \\
\hline & & $11.01-13.00$ & 7 \\
\hline & & $\%<11.00$ & 4 \\
\hline \multirow{3}{*}{ Yeme Kalitesi } & \multirow{3}{*}{15} & $3.6<$ Puan & 10 \\
\hline & & $2.4 \leq$ Puan $\leq 3.6$ & 7 \\
\hline & & $2.4<$ Puan & 4 \\
\hline \multirow{3}{*}{ Albeni } & \multirow{3}{*}{10} & 3.6< Puan & 10 \\
\hline & & $2.4 \leq$ Puan $\leq 3.6$ & 7 \\
\hline & & $2.4<$ Puan & 4 \\
\hline \multirow{3}{*}{$\begin{array}{c}\text { Meyve eti } \\
\text { sertliği } \\
\left(\mathrm{kg} / \mathrm{cm}^{2}\right)\end{array}$} & \multirow{3}{*}{10} & $\mathrm{~kg} / \mathrm{cm}^{2}>9.00$ & 10 \\
\hline & & $6.01-9.00$ & 7 \\
\hline & & $\mathrm{kg} / \mathrm{cm}^{2}<6.00$ & 4 \\
\hline
\end{tabular}

\section{Meyve örneklerinde fiziksel ölçüm bulguları}

Çalışmada işaretlenen ağaçlardan alınan meyve örneklerinde pomolojik analizler gerçekleştirilmiştir. Meyve örneklerinin fiziksel ölçümlerinde; ortalama meyve ağırlığı 65.40 g (44.KM.11) - 205.30 g (44.KM.02), meyve çapı 51.65 mm (44.KM.09) - 75.34 $\mathrm{mm}$ (44.KM.02), meyve boyu $50.31 \mathrm{~mm}$ (44.KM.03)$73.06 \mathrm{~mm}$ (44.KM.02), meyve eti sertliği $5.04 \mathrm{~kg} / \mathrm{cm}^{2}$ (44.KM.01)- $9.40 \mathrm{~kg} / \mathrm{cm}^{2}$ (44.KM.14), meyve sapı uzunluğu $7.48 \mathrm{~mm}$ (44.KM.10)-27.96 mm (44.KM.01), sap çukuru derinliği $6.36 \mathrm{~mm}$ (44.KM.09) - $15.70 \mathrm{~mm}$ (44.KM.02), çiçek çukuru derinliği ise $3.06 \mathrm{~mm}$ (44.KM.14)-10.50 mm (44.KM.07) arasinda değişmiştir. Meyve kabuk rengi ölçümlerinde $L$ renk değeri 41.91 (44.KM.10)-65.62 (44.KM.11), a renk değeri 8.37 (44.KM.13)-32.19 (44.KM.10), b renk değeri ise 15.71 (44.KM.10) - 28.61 (44.KM.11) arasında değişmiştir (Çizelge 3).

\section{Meyve örneklerinde kimyasal ve duyusal analiz bulguları}

Çalışma kapsamında Karamehmet elması klonlarından edilen meyve sularında kimyasal ölçümler yapılmıştır. Gerçekleştirilen kimyasal analizlerde iki ylllık ortalama değer üzerinden; SÇKM oranı \% $10.07 \quad$ (44.KM.01)-\%14.10 ( 44.KM.15), pH değeri 2.20 (44.KM.08) - 3.65 
(44.KM.15), malik asit cinsinden TEA değeri ise \% 0.66 (44.KM.11) - \% 1.12 (44.KM.06) arasında değişmiştir. Çalışmada gerçekleştirilen duyusal analizlerde 44.KM.02, 44.KM.08 ve 44.KM.15 no'lu klonların yeme kalitesi ve albeni yönüyle üstün özellik gösterdikleri belirlenmiștir. Aynı zamanda bu klonların periyodisite eğilimi göstermediği ve verimli oldukları gözlenmiştir (Çizelge 4).

\section{Klonların tartılı derecelendirme puanları}

Ümitvar klonların belirlenmesi için gerçekleştirilen tartılı derecelendirmede, klonların puanları 520 (44.KM.01) ile 970 (44.KM.02) arasında değişmiştir. Klonların aldıkları toplam puanlar üzerinden yapılan değerlendirmede; 44.KM.15, 44.KM.08 ve 44.KM.02 no'lu klonlar ümitvar olarak seçilmiştir (Çizelge 5).

Çizelge 2. İşaretlenen klonların konum ve hasat dönemi bilgileri

\begin{tabular}{|c|c|c|c|c|c|}
\hline Klon no & İl & İlçe & Mahalle / Köy & Rakım (m) & Hasat Tarihi \\
\hline 44.KM.01 & Malatya & Yeşilyurt & Yenimahhale & 1130 & 3-7 Eylül \\
\hline 44.KM.02 & Malatya & Yeşilyurt & Așağıbağlar Mahalesi & 1099 & 3-7 Eylül \\
\hline 44.KM.03 & Malatya & Yeşilyurt & Bahçebaşı Mahallesi & 1120 & 3-7 Eylül \\
\hline 44.KM.04 & Malatya & Yeşilyurt & Konak Mahallesi & 1103 & 3-7 Eylül \\
\hline 44.KM.05 & Malatya & Yeşilyurt & Bahçebaşı Mahallesi & 1104 & 3-7 Eylül \\
\hline 44.KM.06 & Malatya & Yeşilyurt & Gündüzbey Mahallesi & 1165 & 3-7 Eylül \\
\hline 44.KM.07 & Malatya & Yeşilyurt & Su Mahallesi & 1127 & 3-7 Eylül \\
\hline 44.KM.08 & Malatya & Yeşilyurt & Konak Mahallesi & 1130 & 3-7 Eylül \\
\hline 44.KM.09 & Malatya & Yeşilyurt & Bahçebaşı Mahallesi & 1092 & 3-7 Eylül \\
\hline 44.KM.10 & Malatya & Yeşilyurt & Bahçebaşı Mahallesi & 1102 & 3-7 Eylül \\
\hline 44.KM.11 & Malatya & Yeșilyurt & Su Mahallesi & 1079 & 3-7 Eylül \\
\hline 44.KM.12 & Malatya & Yeşilyurt & Yenimahhale & 1129 & 3-7 Eylül \\
\hline 44.KM.13 & Malatya & Yeşilyurt & Su Mahallesi & 1074 & 3-7 Eylül \\
\hline 44.KM.14 & Malatya & Yeşilyurt & Konak Mahallesi & 1136 & 3-7 Eylül \\
\hline 44.KM.15 & Malatya & Darende & Ayvalı Köyü & 1328 & 5-10 Eylül \\
\hline
\end{tabular}

Çizelge 3. Meyve örneklerinde ki yıllık ortalama fiziksel ölçüm değerleri

\begin{tabular}{|c|c|c|c|c|c|c|c|c|c|c|}
\hline Klon No & $\begin{array}{c}\text { Meyve } \\
\text { A ̆ğlrlığl (g) }\end{array}$ & $\begin{array}{c}\text { Meyve } \\
\text { Çapı (mm) }\end{array}$ & $\begin{array}{c}\text { Meyve } \\
\text { boyu (mm) }\end{array}$ & $\begin{array}{l}\text { Meyve Eti } \\
\text { Sertliği } \\
\left(\mathrm{kg} / \mathrm{cm}^{2}\right)\end{array}$ & $\begin{array}{l}\text { Meyve Sapı } \\
\text { Uzunluğu } \\
(\mathrm{mm})\end{array}$ & $\begin{array}{l}\text { Sap çukuru } \\
\text { derinliği } \\
(\mathrm{mm})\end{array}$ & $\begin{array}{c}\text { Çiçek } \\
\text { çukuru } \\
\text { derinliği } \\
\text { (mm) }\end{array}$ & $\mathrm{L}$ & $\mathrm{a}$ & $\mathrm{b}$ \\
\hline 44.KM.01 & $71.98 \pm 8.91$ & $54.40 \pm 5.89$ & $52.75 \pm 6.58$ & $5.04 \pm 0.25$ & $27.96 \pm 2.15$ & $8.50 \pm 1.68$ & $6.75 \pm 1.23$ & 61.62 & 10.09 & 24.41 \\
\hline 44.KM.02 & $205.30 \pm 10.94$ & $75.34 \pm 6.58$ & $73.06 \pm 4.98$ & $7.90 \pm 0.82$ & $22.85 \pm 3.22$ & $15.70 \pm 2.01$ & $8.32 \pm 1.15$ & 59.42 & 12.41 & 18.90 \\
\hline 44.KM.03 & $67.00 \pm 7.56$ & $52.37 \pm 7.85$ & $50.31 \pm 7.28$ & $9.00 \pm 1.01$ & $10.62 \pm 2.41$ & $10.25 \pm 1.89$ & $5.23 \pm 2.01$ & 45.54 & 24.88 & 16.09 \\
\hline 44.KM.04 & $103.50 \pm 9.21$ & $59.74 \pm 5.47$ & $58.75 \pm 6.54$ & $7.66 \pm 0.25$ & $14.18 \pm 2.36$ & $9.97 \pm 1.25$ & $8.82 \pm 2.25$ & 53.71 & 12.72 & 21.03 \\
\hline 44.KM.05 & $74.42 \pm 7.28$ & $52.86 \pm 6.98$ & $50.50 \pm 5.47$ & $7.82 \pm 0.85$ & $14.55 \pm 3.25$ & $7.63 \pm 1.85$ & $5.70 \pm 1.24$ & 62.52 & 9.12 & 25.42 \\
\hline 44.KM.06 & $88.96 \pm 8.54$ & $56.90 \pm 4.58$ & $52.44 \pm 6.85$ & $7.94 \pm 0.54$ & $15.35 \pm 3.01$ & $8.31 \pm 2.01$ & $8.03 \pm 1.85$ & 55.15 & 10.92 & 21.70 \\
\hline 44.KM.07 & $104.66 \pm 9.58$ & $61.22 \pm 5.47$ & $58.39 \pm 5.28$ & $7.48 \pm 0.45$ & $16.07 \pm 2.75$ & $10.16 \pm 1.29$ & $10.50 \pm 2.36$ & 55.16 & 11.78 & 21.71 \\
\hline 44.KM.08 & $151.98 \pm 9.28$ & $71.29 \pm 4.78$ & $68.58 \pm 4.21$ & $7.96 \pm 0.65$ & $15.35 \pm 2.10$ & $8.32 \pm 1.86$ & $8.04 \pm 1.45$ & 58.79 & 10.30 & 22.63 \\
\hline 44.КМ.09 & $71.50 \pm 7.58$ & $51.65 \pm 6.82$ & $50.68 \pm 3.28$ & $7.72 \pm 0.85$ & $15.56 \pm 2.52$ & $6.36 \pm 2.04$ & $5.56 \pm 2.48$ & 55.73 & 13.53 & 21.94 \\
\hline 44.KM.10 & $87.24 \pm 6.97$ & $57.22 \pm 5.28$ & $55.12 \pm 5.74$ & $6.06 \pm 0.81$ & $7.48 \pm 2.01$ & $10.29 \pm 1.25$ & $9.78 \pm 2.34$ & 41.91 & 32.19 & 15.71 \\
\hline 44.KM.11 & $65.40 \pm 8.47$ & $55.92 \pm 4.25$ & $53.64 \pm 6.28$ & $8.60 \pm 0.47$ & $12.53 \pm 1.98$ & $10.23 \pm 2.08$ & $4.80 \pm 1.24$ & 65.62 & 16.77 & 28.61 \\
\hline 44.KM.12 & $67.80 \pm 6.74$ & $53.24 \pm 5.28$ & $51.44 \pm 4.69$ & $7.60 \pm 0.28$ & $24.60 \pm 2.56$ & $6.83 \pm 1.28$ & $5.96 \pm 1.16$ & 62.40 & 10.13 & 20.82 \\
\hline 44.KM.13 & $110.20 \pm 9.56$ & $65.79 \pm 7.63$ & $60.12 \pm 5.96$ & $8.40 \pm 0.45$ & $23.33 \pm 3.12$ & $6.85 \pm 1.85$ & $4.15 \pm 2.01$ & 60.86 & 8.37 & 23.53 \\
\hline 44.KM.14 & $115.50 \pm 7.58$ & $66.21 \pm 6.41$ & $60.89 \pm 6.35$ & $9.40 \pm 0.65$ & $18.86 \pm 2.24$ & $8.99 \pm 2.12$ & $3.06 \pm 1.21$ & 55.25 & 17.74 & 20.13 \\
\hline 44.KM.15 & $175.02 \pm 8.69$ & $72.75 \pm 5.69$ & $71.22 \pm 5.26$ & $8.90 \pm 0.83$ & $18.72 \pm 1.95$ & $9.15 \pm 1.47$ & $7.12 \pm 1.39$ & 56.16 & 18.12 & 23.65 \\
\hline
\end{tabular}

Çizelge 4. Meyve örneklerinde kimyasal ve duyusal analiz bulguları

\begin{tabular}{|c|c|c|c|c|c|c|c|}
\hline Klon no & SÇKM (\%) & $\mathrm{pH}$ & Asitlik (\%) & Periyodisite eğilimi & Verimlilik & Yeme Kalitesi & Albeni \\
\hline 44.KM.01 & $10.07 \pm 1.65$ & $3.15 \pm 0.02$ & $0.78 \pm 0.08$ & Var & Orta & Orta & İyi \\
\hline 44.KM.02 & $13.12 \pm 1.98$ & $3.50 \pm 0.80$ & $0.86 \pm 0.06$ & Yok & İyi & İyi & İyi \\
\hline 44.KM.03 & $11.40 \pm 0.89$ & $3.24 \pm 0.60$ & $0.94 \pm 0.02$ & Kismi & İyi & İyi & İyi \\
\hline 44.KM.04 & $10.50 \pm 1.27$ & $3.14 \pm 0.09$ & $0.97 \pm 0.05$ & Kısmi & Orta & Orta & İyi \\
\hline 44.KM.05 & $10.50 \pm 1.54$ & $3.21 \pm 0.25$ & $0.84 \pm 0.07$ & Kısmi & Orta & Orta & İyi \\
\hline 44.KM.06 & $11.39 \pm 0.96$ & $3.19 \pm 0.07$ & $1.12 \pm 0.12$ & Kısmi & Orta & Orta & İyi \\
\hline 44.KM.07 & $10.50 \pm 1.12$ & $3.23 \pm 0.09$ & $0.86 \pm 0.05$ & Kısmi & Orta & İyi & İyi \\
\hline 44.KM.08 & $13.80 \pm 0.97$ & $2.20 \pm 0.23$ & $1.12 \pm 0.15$ & Yok & İyi & İyi & İyi \\
\hline 44.KM.09 & $12.30 \pm 1.14$ & $3.27 \pm 0.85$ & $1.01 \pm 0.08$ & Kısmi & Orta & Orta & İyi \\
\hline 44.KM.10 & $12.10 \pm 1.28$ & $3.34 \pm 0.27$ & $0.90 \pm 0.02$ & Kısmi & İyi & İyi & İyi \\
\hline 44.KM.11 & $11.40 \pm 0.92$ & $3.34 \pm 0.12$ & $0.66 \pm 0.06$ & Kısmi & Orta & Orta & Orta \\
\hline 44.KM.12 & $10.90 \pm 0.96$ & $3.21 \pm 0.08$ & $0.70 \pm 0.07$ & Kısmi & İyi & İyi & İyi \\
\hline 44.KM.13 & $12.10 \pm 1.28$ & $3.05 \pm 0.36$ & $1.09 \pm 0.18$ & Kısmi & İyi & İyi & Orta \\
\hline 44.KM.14 & $12.40 \pm 0.84$ & $3.14 \pm 0.52$ & $0.78 \pm 0.07$ & Var & İyi & İyi & İyi \\
\hline 44.KM.15 & $14.10 \pm 1.45$ & $3.65 \pm 0.08$ & $0.70 \pm 0.09$ & Yok & İyi & İyi & İyi \\
\hline
\end{tabular}


Çizelge 5. Klonların tartılı derecelendirme puanları

\begin{tabular}{|c|c|c|c|c|c|c|c|c|}
\hline Klon no & $\begin{array}{l}\text { Meyve } \\
\text { ağırlığl }\end{array}$ & $\begin{array}{c}\text { Meyve eti } \\
\text { sertliği }\end{array}$ & SÇKM & $\begin{array}{c}\text { Periyodisite } \\
\text { eğilimi }\end{array}$ & Verimlilik & $\begin{array}{c}\text { Yeme } \\
\text { kalitesi }\end{array}$ & Albeni & Toplam \\
\hline 44.KM.02 & 200 & 70 & 100 & 150 & 200 & 150 & 100 & 970 \\
\hline 44.KM.08 & 140 & 70 & 100 & 150 & 200 & 150 & 100 & 910 \\
\hline 44.KM.15 & 140 & 70 & 100 & 150 & 200 & 150 & 100 & 910 \\
\hline 44.KM.13 & 140 & 70 & 70 & 75 & 200 & 150 & 70 & 775 \\
\hline 44.KM.14 & 140 & 100 & 70 & 15 & 200 & 150 & 100 & 775 \\
\hline 44.KM.03 & 80 & 70 & 70 & 75 & 200 & 150 & 100 & 745 \\
\hline 44.KM.10 & 80 & 70 & 70 & 75 & 200 & 150 & 100 & 745 \\
\hline 44.KM.07 & 140 & 70 & 40 & 75 & 140 & 150 & 100 & 715 \\
\hline 44.KM.12 & 80 & 70 & 40 & 75 & 200 & 150 & 100 & 715 \\
\hline 44.KM.04 & 140 & 70 & 40 & 75 & 140 & 105 & 100 & 670 \\
\hline 44.KM.06 & 80 & 70 & 70 & 75 & 140 & 105 & 100 & 640 \\
\hline 44.KM.09 & 80 & 70 & 70 & 75 & 140 & 105 & 100 & 640 \\
\hline 44.KM.05 & 80 & 70 & 40 & 75 & 140 & 105 & 100 & 610 \\
\hline 44.KM.11 & 80 & 70 & 70 & 75 & 140 & 105 & 70 & 610 \\
\hline 44.KM.01 & 80 & 40 & 40 & 15 & 140 & 105 & 100 & 520 \\
\hline
\end{tabular}

\section{Ümitvar klonların meyve özellikleri}

Çalışmada ümitvar olarak belirlenen klonların meyve özelliklerine ait ortalama değerler detaylı olarak Çizelge 6,7,8' de meyvelere ait resimler ise Şekil 2,3,4' te verilmiştir.

Çizelge 6. 44.KM.02 nolu klonun meyve özellikleri

\begin{tabular}{lc}
\hline Klon no & $44 . \mathrm{KM} .02$ \\
\hline Meyve ağırlı̆̆ı (g) & 205.30 \\
Meyve çapı (mm) & 75.34 \\
Meyve Boyu (mm) & 73.06 \\
Meyve eti sertliği $\left(\mathrm{kg} / \mathrm{cm}^{2}\right)$ & 7.90 \\
Meyve sapı uzunluğu (mm) & 22.85 \\
Sap çukuru derinliği (mm) & 15.70 \\
Çiçek çukuru derinliği (mm) & 8.32 \\
SÇKM (\%) & 13.12 \\
pH & 3.50 \\
Asitlik (\%) & 0.86 \\
\hline
\end{tabular}

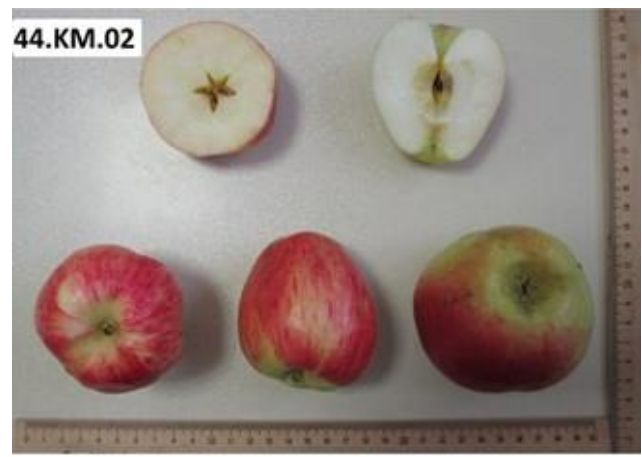

Şekil 2. 44.KM.02 nolu klonun meyveleri

Çizelge 7. 44.KM.08 nolu klonun meyve özellikleri

\begin{tabular}{lc}
\hline Klon no & 44. KM.08 \\
\hline Meyve ağırlı̆̆ (g) & 151.98 \\
Meyve çapı (mm) & 71.29 \\
Meyve Boyu (mm) & 68.58 \\
Meyve eti sertliği $\left(\mathrm{kg} / \mathrm{cm}^{2}\right)$ & 7.96 \\
Meyve sapı uzunluğu (mm) & 15.35 \\
Sap çukuru derinliği (mm) & 8.32 \\
Çiçek çukuru derinliği (mm) & 8.04 \\
SÇKM (\%) & 13.80 \\
pH & 2.20 \\
Asitlik (\%) & 1.12 \\
\hline
\end{tabular}

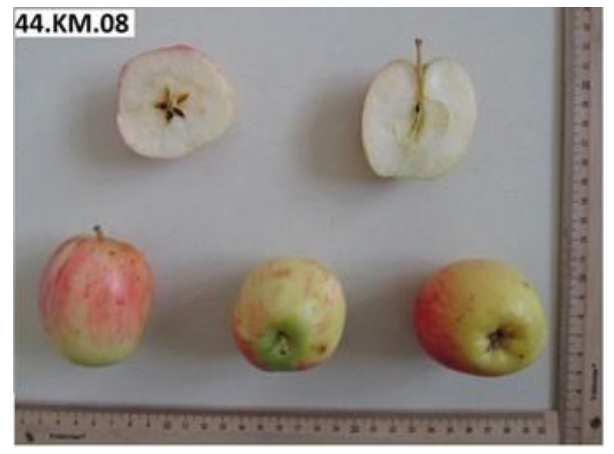

Şekil 3. 44.KM.08 nolu klonun meyveleri

Çizelge 8. 44.KM.15 nolu klonun meyve özellikleri

\begin{tabular}{lc}
\hline Klon no & $44 . \mathrm{KM} .15$ \\
\hline Meyve ağırlı̆̆ (g) & 175.02 \\
Meyve çapı (mm) & 72.75 \\
Meyve Boyu (mm) & 71.22 \\
Meyve eti sertliği $\left(\mathrm{kg} / \mathrm{cm}^{2}\right)$ & 8.90 \\
Meyve sapı uzunluğu (mm) & 18.72 \\
Sap çukuru derinliği (mm) & 9.15 \\
Çiçek çukuru derinliği (mm) & 7.12 \\
SÇKM (\%) & 14.10 \\
pH & 3.65 \\
Asitlik (\%) & 0.70 \\
\hline
\end{tabular}

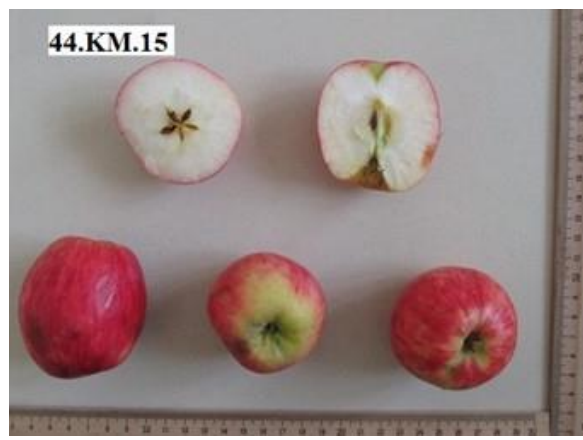

Şekil 4. 44.KM.15 nolu klonun meyveleri

\section{Sonuçlar ve Tartışma}

$\mathrm{Bu}$ çalışmada, Malatya ilinde yetiştirilen mahalli 'Karamehmet' elma çeşidinde üstün özellikli klonlar seçilmiştir. Tartılı derecelendirme yönteminin 
kullanıldığı çalışmada 910 ve üzeri puan alan 44.KM.15, 44.KM.08 ve 44.KM.02 no'lu klonlar ümitvar olarak belirlenmiştir. Ümitvar klonlarda meyve ağırlığı 151.98 g (44.KM.08) ile 205.30 g (44.KM.02) arasında değişmiştir. Meyve ağırlığı değerlerini Akça ve Şen (1990), 20.23 - 236.00 g, Şen ve ark. (1992), 23.95 - 65.5 g, Güleryüz ve Ercişli (1995), 159.0-313.0 g, Balta ve Uca (1996), 110-217 g, Erdoğan ve Bolat (2002), 17.52-258.68 g, Kaplan ve ark. (2002), 90.40-161.86 g, Serdar ve ark. (2007), $54.3 \mathrm{~g}$ - $206.0 \mathrm{~g}$, Edizer ve Bekar (2007), 48.0-311.0 $\mathrm{g}$, İslam ve ark. (2009), 72.185-113.385 g, Kaya ve Balta (2009), 92.18 - 310.99 g, Aygün ve Ülgen (2009), 60.7-163.4 g, Yılmaz (2010), 72.19-113.39 g, Özrenk ve ark. (2011), 20.9-139.3 g, Kırkaya ve ark.(2014), 76.24-247.23 g, Açlk (2015), 67.23194.96 g, Arıkan ve ark. (2015), 97.48-177.96 g, Balta ve ark. (2015), 71.41-245.99 g, Şenyurt ve ark. (2015), 80.70-195.61 g, Coşkun ve Așkın (2016), 96.99-184.25 g, Karakaya ve ark. (2016), 76.18 244.12 g, Karşı ve Aslantaş (2016), 51.35-183.16 g, Güneş ve Coşkun (2018), 28.72-430.76 g, Çöçen ve ark.(2018), ise 221.74-232.88 g arasında bulmuştur. Elde ettiğimiz meyve ağırlığı değerinin diğer araştırmacıların sonuçlarıyla benzer olduğu görülmektedir. Ümitvar klonlarda meyve eti sertliği değerleri $7.90 \mathrm{~kg} / \mathrm{cm}^{2}$ (44.KM.02) ile $8.90 \mathrm{~kg} / \mathrm{cm}^{2}$ (44.KM.15) arasında belirlenmiştir. $\mathrm{Bu}$ değerleri Doğan ve Güleryüz (2007), 6.60 - $8.40 \mathrm{lb}$, Serdar ve ark.(2007), $4.9-10.4 \mathrm{~kg} / \mathrm{cm}^{2}$, İslam ve ark. (2009), 5.60-8.20 kg/ $\mathrm{cm}^{2}$, Özrenk ve ark.(2011), 3.9-6.2 $\mathrm{kg} / \mathrm{cm}^{2}$, Kaplan ve ark. (2002), 3.90-4.57 kg/ $\mathrm{cm}^{2}$, Kırkaya ve ark.(2014), 6.99-12.83 lb, Açık (2015), 6.25-10.07 lb, Balta ve ark. (2015), 6.94-12.64 lb, Çöçen ve ark. (2018) ise 5.07-5.22 kg/ $\mathrm{cm}^{2}$ arasında belirlemiştir. Diğer araştırmacıların buldukları değerlerin, bizim değerlerimize göre daha geniş bir aralıkta olduğu görülmektedir. $\mathrm{Bu}$ durumun çalışmalarda ele alınan materyal farklılığından kaynaklandığı düşünülmektedir.

Çalışmamızda ümitvar klonlarda SÇKM değerleri \%13.12 (44.KM.02) ile \%14.10 (44KM.15) arasında değişmiştir. Bu değerleri Akça ve Şen (1990), \% 8.00 -15.35, Güleryüz ve Ercişli (1995), \% 12.35-14.45, Prrlak ve ark.(1997), \% 10.3-13.8, Erdoğan ve Bolat (2002), \% 11.50-14.50, Edizer ve Bekar (2007), \% 916, Aygün ve Ülgen ( 2009), \% 10.6-13.00, Serdar ve ark. (2007), \% 8.5 - 13.7, Özrenk ve ark. (2011), \%10.0 -15.4, Kırkaya ve ark. (2014), \% 9.01-13.75, Açlk (2015), \% 8.50-14.50, Balta ve ark. (2015), \% 9.40-13.60, Vurgun ve Aslantaş (2015), \% 12.90-
18.25, Bostan ve Yılmaz (2015), Yomra elmasında \% 12-15 Demir elmasında \% 13.85-15.75, Coşkun ve Așkın (2016), \% 11.27-14.23, Karakaya ve ark. (2016), \% 8.40-14.25, Karşı ve Aslantaş (2016), \% 7.73-14.60, Uzun ve ark. (2016), \% 7.67-14.10, Güneș ve Coşkun (2018) ise \% 11.66-15.83 arasında değiștiğini bildirmektedir. Belirlediğimiz değerlerin diğer araştırmaların verileriyle uyum içerisinde olduğu görülmektedir. Çalışmamızda ümitvar klonlarda TEA değerinin \% 0.70 (44.KM.15) ile \%1.12 (44.KM.08) arasında değiştiği belirlenmiştir. $\mathrm{Bu}$ değerleri Şen ve ark. (1992), \% 0.19 - 0.90, Güleryüz ve Ercişli (1995), \% 0.29-0.44, Purlak ve ark. (1997), \% 0.19-1.43, Erdoğan ve Bolat (2002), \% 0.21-0.87, Serdar ve ark. (2007), \% 0.2-1.3, Aygün ve Ülgen (2009), \% 0.7-1.2, Yarılgaç ve ark.(2009), \% 0.699-0.929, Kazankaya ve ark. (2009b), \% 0.171.10, Kaya ve Balta (2013a), \% 0.12-1.55, Kaya ve Balta (2013b), \% 0.15-3.58, Balta ve ark. (2015), \% 0.22-2.01, Karakaya ve ark. (2016), \% 0.16-1.08, Uzun ve ark. (2016) ise \% 0.11-1.07 arasında belirlemişlerdir. Belirlediğimiz TEA değerinin diğer araştırmacıların sonuçlarıyla paralellik arz ettiği görülmektedir. Ümitvar klonlarda $\mathrm{pH}$ değeri 2.20 (44.KM.08) ile 3.65 (44.KM.15) arasında değişmiştir. Bu parametreyi Şen ve ark. (1992), 3.42-3.89, Özkan ve Celep (1995), 2.92-3.38, Karadeniz ve ark. (1996), 2.79-4.70, Erdoğan ve Bolat (2002), 3.444.92, Osmanoğlu (2008), 4.26-5.80, Kazankaya ve ark. (2009a), 3.66-4.82, Kazankaya ve ark. (2009b), 3.43-4.08, Yarılgaç ve ark. (2009), 3.60-4.82, Çorumlu (2010), 3.94-6.20, Doğru (2012), 4.26-5.80, Karadeniz ve ark. (2013), 3.88-4.28, Kaya ve Balta (2013a), 3.14-4.79, Kaya ve Balta (2013b), 3.44 4.55, Açlk (2015), 3.01-4.84, Balta ve ark. (2015), 2.83-4.11, Karakaya ve ark. (2016) ise 2.89-4.80 arasında belirlemiştir. Elde ettiğimiz pH değerlerinin diğer araştırmacıların sonuçlarıyla uyum içerisinde olduğu görülmektedir. Çalışmamızda ümitvar olarak belirlenen klonların verimli oldukları ve periyodisite eğilimi göstermedikleri görülmüştür. Ayrıca bu klonlara ait meyvelerin yeme kalitesi ve albeni yönüyle de üstün özellikte oldukları belirlenmiştir. Çalışma sonunda ümitvar klonlar Kayısı Araștırma Enstitüsü Müdürlügü elma koleksiyon parseline aktarılmıştır.

\section{Kaynaklar}

Anonim, 2009. Elma Yetiștiriciliği, Milli Eğitim Bakanlığı Yayınları, (MEGEP), Ankara. 123 s.

Akça Y, Şen SM, 1990. Van ve çevresinde yetiştirilen mahalli elma çeşitlerinin morfolojik ve pomolojik 
özellikleri üzerine bir araştırma, Y.Y.Ü.Z.F. Dergisi I (1): 109-128.

Altan, A., 1989. Laboratuvar Tekniği. Çukurova Üniversitesi, Ziraat Fakültesi, Ders Kitabı No:36, s. 172, Adana.

Açık, F., 2015. Gürgentepe (Ordu) İlçesinde Yetiştirilen Yerel Elma Çeşitlerinin Meyve ve Ağaç Özellikleri, Yüksek Lisans Tezi, Ordu Üniversitesi, Fen Bilimleri Enstitüsü, Bahçe Bitkileri Anabilim Dalı, Ordu, $68 \mathrm{~s}$

Arıkan, Ş., İpek, M., Pırlak, L., 2015. Konya ekolojik şartlarında bazı elma çeşitlerinin fenolojik ve pomolojik özelliklerinin belirlenmesi. Türk Tarım Gıda Bilim ve Teknoloji Dergisi, 3 (10) : 811-815.

Aygün, A., ve Ülgen, S.A., 2009. Rize'de yetiştirilen Demir Elma (Malus cammunis L.) çeşidinin bazı meyve özelliklerinin belirlenmesi. Tarım Bilimleri Araştırma Dergisi, 2 (2) : 201-205.

Balta, M.F., Kaya, T., Kırkaya, H., Karakaya, O., 2015. Kumru (Ordu) yöresinde yetiştirilen mahalli elma genotiplerinin fenoljik, morfolojik ve pomolojik özellikleri. Gaziosmanpaşa Üniversitesi Ziraat Fakültesi Dergisi, 32 (1):47-56.

Balta, F., Uca, O., 1996. Iğdır'da yetiştirilen önemli yazlık mahalli elma çeşitlerinin morfolojik ve pomolojik özellikleri. Y.Y.Ü. Ziraat Fakültesi Dergisi, 6(1) : 87 95.

Bayındır, Y., Çöçen, E., Macit, T., Gültekin, N., Toprak Özcan, E., Aslan, A., Aslantaş, R., 2018. Malatya yöresi mahalli güzlük armut genotiplerinin seleksiyonu. Akademik Ziraat Dergisi, 7 (1): 9-16.

Bostan, S.Z., Yılmaz, E., 2015. Breeding by selection of 'Yomra' and 'Demir' apple varieties (Malus communis L.) grown in Arsin and Yomra districts (Trabzon Province, Turkey). Meyve Bilimi, 2 (1): 60-69.

Burak, M., Büyükyılmaz, M., Öz, F., 1997. Granny Smith elma çeşidinin farklı anaçlar üzerindeki verim ve kalite özelliklerinin belirlenmesi, Yumuşak Çekirdekli Meyveler Sempozyumu, Yalova, 61-68.

Coşkun, S., Aşkın, M.A., 2016. Bazı yerli elma çeşitlerinin pomolojik ve biyokimyasal özelliklerinin belirlenmesi, Süleyman Demirel Üniversitesi Ziraat Fakültesi Dergisi, 11 (1) : 120-131.

Çorumlu, M.S., 2010. Çorum İli İskilip İlçesinde Yetiştirilen Bazı Yerel Elma (Malus communis L.) Çeşitlerinin Fenolojik Ve Pomolojik Özelliklerinin Belirlenmesi, Ordu Üniversitesi, Fen Bilimleri Enstitüsü, Yüksek Lisans Tezi, 92s, Ordu.

Çöçen, E., Macit T., Ernim C., Kokargül R., Uğur Y., Kan T., Pirlak L., 2018. Malatya yöresinde yetiştirilen
"Arapkızı"' elma çeşidinde klon seleksiyonu, Meyve Bilimi; 5(2):43-48.

Doğan, A., Güleryüz, M., 2007. Sakı elma çeşidinde klon seleksiyonu. Türkiye 5. Ulusal Bahçe Bitkileri Kongresi Bildiriler Kitabı, sayfa 185-189, 04-07 Eylül 2007, Erzurum.

Doğru, B., 2012. Çorum İli İskilip İlçesinde Yetiştirilen Mahalli Misket Elmalarının Fenolojik, Morfolojik, Pomolojik Özelliklerinin Belirlenmesi ve Moleküler Olarak Tanımlanması. Ordu Üniversitesi, Fen Bilimleri Enstitüsü, Yüksek Lisans Tezi, Ordu, 122 s.

Edizer, Y., Bekar, T., 2007. Tokat merkez ilçede yetiştirilen bazı yerel elma (Malus communis L.) çeşitlerinin fenolojik ve pomolojik özelliklerinin belirlenmesi. GOÜ. Ziraat fakültesi Dergisi, 24 (1) : 1-8.

Erdoğan, Ü.G., 2002. Çoruh Vadisinde yetiştirilen bazı elma çeşitlerinin fenolojik ve pomolojik özelliklerinin incelenmesi. Bahçe 31 (1-2) : 25-32.

FAO, 2018. Dünya Gıda ve Tarım Örgütü (http://www.fao.org/faostat/en/\#data/QC).

Güleryüz, M., Ercişli, S., 1995. Kağızman İlçesinde yetiştirilen mahalli elma çeşitleri üzerindeki biyolojik ve pomolojik araştırmalar. Atatürk Üniv. Zir. Fak. Der. $26(2): 183-193$.

Güneș, A., Dutgaç, C., 2018. Gülnar Yöresinde yetiştirilen elma genotiplerinin morfolojik, feolojik, pomolojik ve moleküler tanımlaması. Moleküler Biyoloji ve Biyoteknoloji Dergisi 2 (1): 28-33.

İslam, A., Bostan, Z., Yılmaz, E., 2009. Trabzon İli Yomra İlçesinde yetişen Yomra Elmasının pomolojik özellikleri üzerine bir araștırma. Tarım Bilimleri Araștırma Dergisi 2 (2) : 107-110.

Kaçal, E., Öztürk, G., Atay, N., Sarısu, C., Özongun, Ş., Atay, E., Emre, R.A., Yürekli, Ö., Karamürsel, Ö.F., 2009. Eğirdir Bahçe Kültürleri Araştırma Enstitüsü elma ıslah çalışmaları. Tarım Bilimleri Araştırma Dergisi, 2(1):53-56.

Karadeniz, T., Gökalp, G., Kabay, T., 1996. Ulus ve Maden çevresinde yetiştirilen mahalli elma çeşit ve tipleri üzerinde pomolojik ve morfolojik çalışmalar. Yüzüncü Yıl Üniv. Ziraat Fak. Dergisi, 6 (2) : 115125.

Karadeniz, T., Akdemir, E.T., Yılmaz, İ., Aydın, H., 2013. Piraziz elmasında klon seleksiyonu, Akademik Ziraat Dergisi 2 (1) :17-22.

Karlıdağ, H., Eşitken, A., 2006. Yukarı Çoruh Vadisinde yetiştirilen elma ve armut çeşitlerinin bazı pomolojik özelliklerinin belirlenmesi. Yüzüncü Yıl Üniversitesi Ziraat Fakültesi Tarım Bilimleri $\begin{array}{llll}\text { Dergisi, } & 16 & \text { (2) } & \text { : }\end{array}$ 
Kaplan, N., Özcan, M., Çelik, M., 2002. Amasya elmasında klon seleksiyonu. Ondokuz Mayıs Üniversitesi Ziraat Fakültesi Dergisi, 17 (1) :49-56.

Kaşka, N., 1997. Türkiye'de elma yetiştiriciliğinin önemi, sorunları ve çözüm yolları. Yumuşak Çekirdekli Meyveler Sempozyumu. Yalova. 1-12.

Karakaya, O., Balta, M.F., Kaya, T., Uzun, S., 2016. Yağlıdere (Giresun) elmaları: Fenolojik ve pomolojik özellikleri. Bahçe, Özel Sayı ( VII. Ulusal Bahçe Bitkileri Kongresi Bildirileri, Cilt-1 : 925-929.

Karşı, T., Aslantaş, R., 2016. Erzurum'da yetiştirilen bazı elma (Malus communis L.) çeşitlerinin fenolojik, pomolojik ve kimyasal özelliklerinin belirlenmesi. Atatürk Üniv. Ziraat Fakültesi Dergisi 47(1): 11-21.

Kaya, T., Balta, F., 2009. Van Yöresi elma seleksiyonları 1: Periyodisite göstermeyen genotipler. Tarım Bilimleri Araştırma Dergisi, 2 (2): 25-30.

Kaya, T., Balta, F., 2013a. Van Yöresi Elma seleksiyonları-3: Periyodisite eğilimi bulunan genotipler. Ordu Üniversitesi Bil. Tek. Derg., 3 (2) : 29-38.

Kaya, T., Balta, F., 2013b. Van Yöresi elma seleksiyonları-2: Periyodisiteye kısmi eğilim gösteren genotipler. Akademik Ziraat Dergisi, 2 (2) :91-98.

Kazankaya, A., Yonar, Y., Başer, S., Çelik, F., Doğan, A., Yaviç, A., 2009a. Adilcevaz (Bitlis) Yöresinde doğal olarak yetişen elmaların bazı meyve ve ağaç özellikleri, Tarım Bilimleri Araştırma Dergisi, 2 (2) : 81-87.

Kazankaya, A., Yonar, Y., Başer, S., Çelik, F., Doğan, A., Yaviç, A., 2009b. Erciş ve Muradiye Yörelerinde doğal olarak yetișen elmaların bazı meyve ve ağaç özellikleri, Tarım Bilimleri Araştırma Dergisi, 2 (2): 89-94.

Kırkaya, H., Balta, F.M., Kaya, T., 2014. Perşembe (Ordu/Türkiye) yöresinde yetiștirilen elma genotiplerinin pomolojik, morfolojik ve fenolojik özellikleri, Iğdır Üniversitesi Fen Bilimleri Enstitüsü Dergisi 4 (3) : 15-20.

Küçükömürler, S., Karakuş, S.Ş., 2009. Elma, sağlık ve kültür. Tarım Bilimleri Araștırma Dergisi 2 (1):183186.

Osmanoğlu, A., 2008. Posof (Ardahan) Yöresi Elma Genetik Kaynaklarının Fenolojik, Morfolojik, Pomolojik ve Moleküler Tanımlanması, Yüzüncü Yıl Üniversitesi, Fen Bilimleri Enstitüsü, Doktora Tezi, Van, $179 \mathrm{~s}$.

Özkan, Y., Celep, C., 1995. Tokat ilinde yetiştirilen yerel elma çeşitlerinin pomolojik özellikleri üzerine bir araştırma, Gaziosmanpaşa Üniversitesi Ziraat Fakültesi Dergisi, 12 (1) : 8-14.
Özrenk, K., Gündoğdu, M., Kaya, T., Kan, T., 2011. Çatak ve Tatvan yörelerinde yetiştirilen yerel elma çeșitlerinin pomolojik özellikleri. YYÜ Tarım Bilimleri Dergisi, 21(1):57-63.

Pearce, S.C., 1976. Field Experimentation with Fruit Trees and other Perennial Plants, Technical Communication, No: 23. CAB, London, 182 p.

Pırlak, L., Güleryüz, M., Aslantaş, R., Eşitken, A., 1997. Erzurum ilinin Tortum ve Uzundere ilçelerinde yetişen yazlık elma tiplerinin seleksiyon yoluyla ıslahı üzerine bir araștırma. Yumuşak Çekirdekli Meyveler Sempozyumu, Yalova.

Serdar, Ü., Ersoy, B., Öztürk, A., Demirsoy, H., 2007. Saklı Cennet Camili 'de yetiştirilen yerel elma çeşitleri. V. Ulusal Bahçe Bitkileri Kongresi, 4-7 Eylül 2007, Erzurum. Cilt: 1 s 575-579.

Şen, S.M., Bostan, S.Z., Cangi, R., Kazankaya, A., Oğuz, H.İ., 1992. Ahlat'ta yetiştirilen önemli mahalli elma çeșitlerinin morfolojik ve pomolojik özellikleri üzerinde bir araștırma. Yüzüncü Yıl Üniversitesi Ziraat Fakültesi Dergisi, 2 (2) : 53-65.

Şenyurt, M., Kalkışım, Ö., Karadeniz, T., 2015. Gümüşhane yöresinde yetiştirilen bazı standart ve mahalli elma (Malus communis L.) çeşitlerinin pomolojik özellikleri, Akademik Ziraat Dergisi 4(2):59-64

TUİK, 2018.Türkiye İstatistik Kurumu, (biruni.tuik.gov.tr).

Uzun, S., Balta, M.F., Kaya, T., Karakaya, O., 2016. Çamaș (Ordu) Yöresinde Yetişen yerel elma genotiplerinin fenolojik ve pomolojik özellikleri. Bahçe, Özel Sayı (VII. Ulusal Bahçe Bitkileri Kongresi Bildirileri, Cilt 1, Meyvecilik) : 653-657.

Ülkümen, L., 1938. Malatya'nın mühim meyve çeşitleri üzerinde morfolojik, fizyolojik ve biyolojik araştırmalar. Yüksek Ziraat Enstitüsü Rektörlüğü, Ankara, sayı 65.

Vurgun, H., Aslantaş R., 2015. Doğu Anadolu Bölgesi elma genotiplerinin morfolojik karakterizasyonu. Atatürk Üniv. Ziraat Fak. Derg., 46 (1) : 1-19.

Yılmaz, E., 2010.Yomra ve Arsin İlçelerinde (Trabzon) Yetiştirilmekte Olan "Yomra ve Demir" Elma Tiplerinin (Malus communis L.) Seleksiyon Yoluyla Islahı, Ordu Üniversitesi, Fen Bilimleri Enstitüsü, Yüksek Lisans Tezi, Ordu, 120 s.

Yarılgaç, T., Karadeniz, T., Gürel, H.B., 2009. Ordu merkez ilçede yetiştirilen yöresel elma (Malus communis L.) çeșitlerinin fenolojik ve pomolojik özelliklerinin belirlenmesi. Tarım Bilimleri Araştırma Dergisi, 2 (2) 